\title{
DEPENDÊNCIA DO REPASSE PREVIDENCIÁRIO: ANÁLISE NA ECONOMIA MUNICIPAL BRASILEIRA
}

\author{
Mariana Sena Lara*
}

\section{Resumo}

A Previdência Social se caracteriza por ser um seguro social para a pessoa que contribui, de modo que a renda transferida é utilizada para substituir a renda do trabalhador contribuinte, quando ele perde a capacidade de trabalho. Assim, é considerada uma das maiores distribuidoras de renda do país e seus efeitos centram-se na redução da pobreza e das desigualdades das regiões. Para atingir tal finalidade, em muitos casos, ocorrem efeitos indesejáveis sobre as economias locais e, sobretudo na distribuição de renda (poder de compra e massa salarial). Nesse sentido, visando contribuir com o debate sobre o tema, o presente trabalho pretende identificar os municípios dependentes das transferências de renda da Previdência Pública utilizando como metodologia a Análise de Componentes Principais e Cluster K-means. Como resultado obteve-se cinco classificações que identificaram os grupos e posteriormente gerou a análise mais apurada em relação ao indicador de dependência criado para ressaltar os municípios que de fato dependem do repasse previdenciário. $O$ indicador focou nos municípios identificados como os mais dependentes embasados no rendimento domiciliar obtido por meio do Censo Demográfico 2010.

Palavras-chave:Previdência Pública, rendimento, municípios dependentes, economia sem produção.

\footnotetext{
"Programa de Pós-Graduação em Análise e Modelagem de Sistemas Ambientais - Universidade Federal de Minas Gerais UFMG.marianasena.geo@gmail.com 


\section{1-INTRODUÇÃO}

O sistema previdenciário brasileiro começou a ser entendido como um instrumento necessário para o financiamento dos indivíduos após a atividade laboral a partir do século XX. Segundo Tonatto (2003), o ponto de partida foi com a criação da Lei Eloy Chaves por meio do decreto-lei 4.682, de 24 de janeiro de 1923 que criava a Caixas de Aposentadoria e Pensões (CAPs) nas empresas ferroviárias com intuito de segurar seus empregados quando não pudessem mais exercer as atividades. A partir daí, despontou como política pública de caráter permanente e geral embasada em um sistema de filiação obrigatória. E, em 1945, no governo Getúlio Vargas, “criou o Instituto de Serviço Social do Brasil (ISSB), cuja função era unificar as instituições previdenciárias existentes e centralizar o seguro social de toda população ativa no país." (Idem, 2003, p. 18). Existiam dois regimes de previdência social: o urbano e o rural, este último tinham o direito de um salário mínimo caso comprovassem o tempo de serviço. Foi a partir da Constituição de 1988, promulgada em 5 de outubro, que passou a ter-se a unificação dos beneficiários e o Regime Geral de Previdência Social.

Ao longo dos anos a Previdência passou por várias mudanças conceituais e estruturais, envolvendo o grau de cobertura, o elenco de benefícios oferecidos e a forma de financiamento do sistema. É uma das principais formas que o governo possui na atuação social - considerando financiamentos essencialmente governamentais. Hoje, se caracteriza por ser um seguro social para a pessoa que contribui, de modo que a renda transferida pela Previdência Social (instituição) é utilizada para substituir a renda do trabalhador contribuinte, quando ele perde a capacidade de trabalho, seja pela doença, invalidez, idade avançada, morte e desemprego involuntário, ou mesmo a maternidade e a reclusão (Ministério da Previdência Social, 2013).

Sendo assim a expansão das transferências de renda direta no Brasil, como parte dos esforços para redução da pobreza e desigualdade, iniciada em 1988 e com a aprovação da Lei Orgânica da Assistência Social - que deu origem às Aposentadorias Rurais e o Benefício de Prestação Continuada - atingiu uma grande abrangência a partir de 2004, com o início da vigência do Programa Bolsa Família ${ }^{1}$. Segundo o Ipea (2013)um dos melhores Programas no Brasil, no quesito distribuição, pois abrange cerca de 13,8 milhões de famílias, sendo

\footnotetext{
${ }^{1}$ TUPY, Igor S. Impactos dos programas governamentais de transferência de renda sobre a economia do vale do Jequitinhonha. Disponível

em:<https://www.bnb.gov.br/content/aplicacao/eventos/forumbnb2013/docs/2013_ss3_mesa1_impactos_pro gramas_governamentais_transferencia_renda_sobre_economia_vale_jequitinhonha.pdf
} 
responsável por $15 \%$ a $20 \%$ da redução da desigualdade de renda no Brasil, impulsionando a diminuição na taxa de extrema pobreza entre 2001 e 2011 - passando de 8\% para 4,7\% da população brasileira.

Conforme Bertussi e Tejada (2003) é importante distinguir previdência social de assistência social. A primeira é um seguro de contribuição mútua para que haja o recebimento do assegurado no futuro (pagamento dos assegurados mensalmente) e, a segunda, se constitui por aquelas pessoas que não contribuíram mensalmente de forma expressa, ou seja, vivem dos financiamentos governamentais por meio de pagamentos de tributos efetuados pela sociedade.

A Previdência Social brasileira é considerada uma das maiores distribuidoras de renda do país. Dados de 2013 mostram que, até setembro, foram desembolsados cerca de R\$29,4 bilhões no pagamento de 30,821 milhões de benefícios, como aposentadorias, pensões e auxílio-doença (26,681 milhões previdenciários e acidentários e, os demais, assistenciais. As aposentadorias somaram 17,4 milhões de benefícios). Em setembro de 2013 o setor urbano arrecadou R \$24,5 bilhões, representando o segundo maior valor da série histórica desconsiderando os meses de dezembro em que há incremento de receita por causa do $13^{\circ}$ salário. Conforme Figura 1 a maior parte dos benefícios são destinados área urbana, incluídos os assistenciais, aumentando a cada ano em relação ao número de beneficiários (MDS, 2013²).

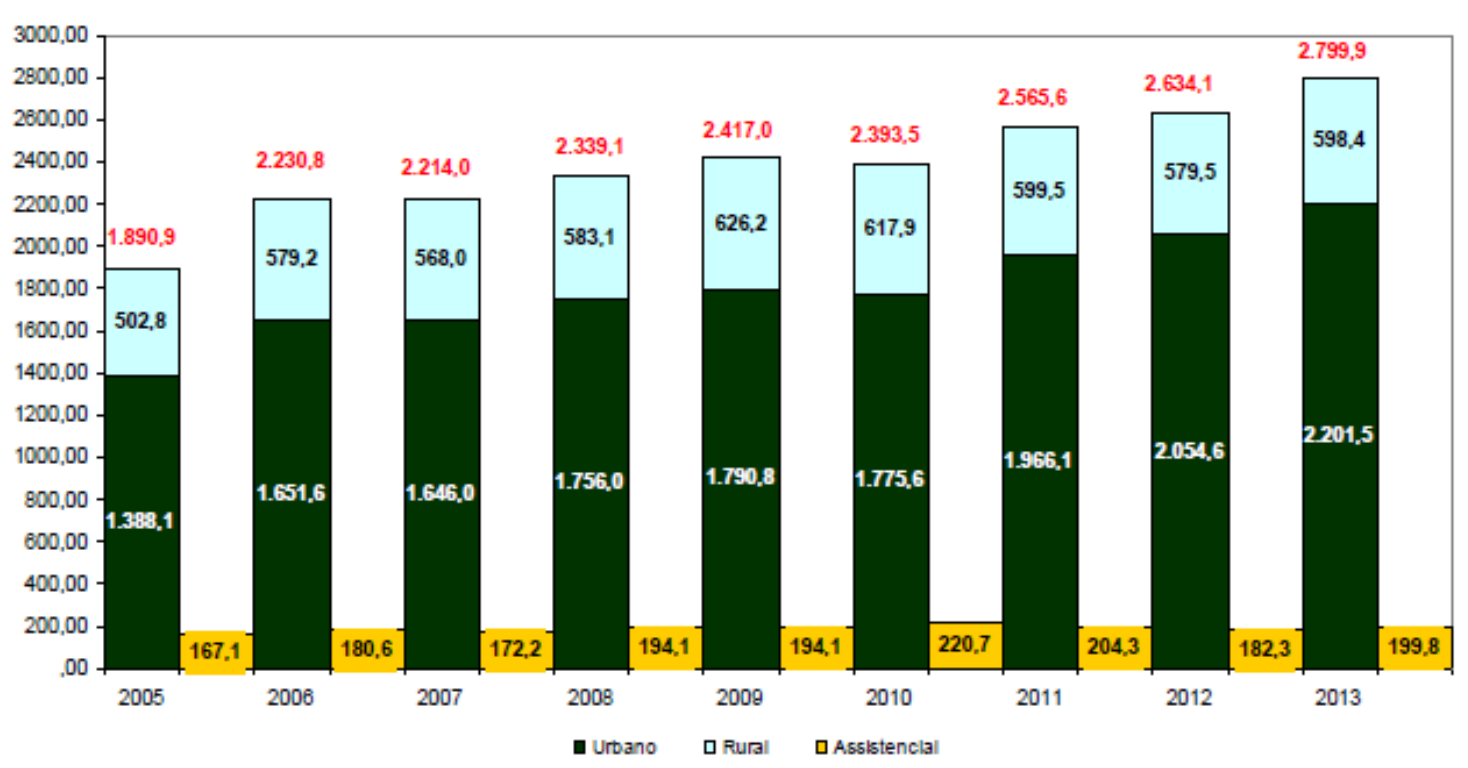

Figura 1:Quantidade de Benefícios Concedidos pela Previdência Social (2005 a 2013) Acumulado de janeiro a julho de cada ano (Em milhares de benefícios) Fonte: Anuário Estatístico da Previdência Social - AEPS; Boletim Estatístico da Previdência Social - BEPS.

${ }^{2}$ SPPS/MPS. APRESENTAÇÃO DO RESULTADO DO REGIME GERAL DE PREVIDÊNCIA SOCIAL RGPS Setembro/2013.Brasília, outubro de 2013SPPS - Secretaria de Políticas de Previdência Social. 
De acordo com Miranda (2010) no contexto nacional a Previdência Social é parte de um sistema mais abrangente, no caso, a Seguridade Social ${ }^{3}$ e, o seu financiamento, que se dá pelo sistema tripartite formado pelos contribuintes, empregadores e Estado, está condicionado às contas do Instituto Nacional do Seguro Social (INSS), que é o órgão responsável pela administração do Sistema de Seguridade Social.

Como dito anteriormente, os efeitos esperados dos benefícios centram-se na redução da pobreza e das desigualdades das regiões. E, muitas vezes, para atingir tal finalidade ocorrem efeitos indesejáveis sobre as economias locais e, sobretudo na distribuição de renda (poder de compra e massa salarial). Dessa forma, esse artigo irá focar na análise desses efeitos indesejáveis como formação da "Economia semProdução", caracterizada por uma dependência na economia municipal dos valores de transferências arrecadados (Bolsa Família, Benefício de Prestação Continuada, Aposentadorias Rurais e Empregos Públicos) como as principais fontes de renda. E, como esses recursos não requerem uma contrapartida produtiva, cria-se uma situação em que a região possui renda, mas não valida a identidade macroeconômica de que renda é igual ao produto. Segundo Gomes (2001) há regiões em que o produto é bem menor que a renda como, por exemplo, ao analisar a ocorrência da "Economia sem Produção" no semi-árido Nordestino. E, caso esses valores transferidos não sejam eficientes no sentido de gerar novas atividades produtivas na região, de forma a elevar a renda per capita das famílias, a geração de empregos e a arrecadação de tributos, corre-se o risco de que se perpetue esta situação.

Nesse sentido, visando contribuir com o debate sobre o tema, o presente trabalho tem como objetivo analisar os impactos das transferências de renda da Previdência Pública sobre as condições de reprodução social das famílias de aposentados e pensionistas nos municípios brasileiros. As principais questões norteadoras serão: quais são os municípios que possuem maior dependência das transferências relativas à Previdência Social e quais os impactos disso na formação da economia municipal?

\section{METODOLOGIA}

\footnotetext{
${ }^{3}$ Segundo Ruprecht (1996, p. 35) “A Seguridade Social implica a aceitação da responsabilidade de toda a sociedade para garantir a segurança econômica a seus membros. Admitida a escolha de formas equitativas de financiamento, a seguridade social vem representar uma solidariedade que não significa um benefício, mas um direito de todos e para todos".
} 
No intuito de entender como se molda a Previdência Pública no Brasil, e na tentativa de gerar mais uma fonte de informação que venha contribuir para a formulação de políticas futuras, o presente artigo abrangerá todo o território nacional na escala municipal. A metodologia se fundamentará em duas partes. A primeira será a análise dos métodos utilizados e, a segunda parte será o entendimento da espacialização dos dados a nível municipal com intuito de traçar o perfil municipal com base nas características da Previdência Pública no Brasil. Os dados relativos, listados na Tabela 1, à Previdência Social, além dos socioeconômicos para embasar a análise com o PIB, POC, PEA, foram:

Tabela 1: Dados referentes à previdência pública brasileira utilizados

\begin{tabular}{|c|c|c|}
\hline Dados & Fonte & Período \\
\hline Quantidade de benefícios emitidos pela previdência social & IBGE/IPEA & 2000 e 2010 \\
\hline Valor arrecadado pela previdência social & IBGE/IPEA & 2000 e 2010 \\
\hline
\end{tabular}

\begin{tabular}{|c|c|c|}
\hline Valor dos benefícios emitidos & $\begin{array}{c}\text { Previdência } \\
\text { Social/MDS }\end{array}$ & 2000 e 2010 \\
\hline $\begin{array}{c}\text { Benefício de Prestação Continuada (BPC) para deficientes - } \\
\text { número de benefícios em dezembro }\end{array}$ & $\begin{array}{c}\text { Previdência } \\
\text { Social/MDS }\end{array}$ & 2004 e 2010 \\
\hline $\begin{array}{c}\text { Beneficio de Prestação Continuada (BPC) para idosos - } \\
\text { número de benefícios em dezembro }\end{array}$ & $\begin{array}{c}\text { Previdência } \\
\text { Social/MDS }\end{array}$ & 2004 e 2010 \\
\hline $\begin{array}{c}\text { Benefício de Prestação Continuada (BPC) para deficientes - } \\
\text { valor total dos beneficios em dezembro }\end{array}$ & IPEA/MDS & 2004 e 2010 \\
\hline $\begin{array}{c}\text { Beneficio de Prestação Continuada (BPC) para idosos - } \\
\text { valor total dos beneficios em dezembro }\end{array}$ & IPEA/MDS & 2004 e 2010 \\
\hline $\begin{array}{c}\text { Programa Bolsa Família (PBF) - valor de beneficios em } \\
\text { dezembro }\end{array}$ & IPEA/MDS & 2004 e 2010 \\
\hline $\begin{array}{c}\text { Renda Mensal Vitalícia (RMV) para deficientes - número } \\
\text { de benefícios em dezembro }\end{array}$ & IPEA/MDS & 2010 \\
\hline $\begin{array}{c}\text { Renda Mensal Vitalícia (RMV) para deficientes - valor } \\
\text { total dos beneficios em dezembro }\end{array}$ & IPEA/MDS & 2010 \\
\hline $\begin{array}{c}\text { Renda Mensal Vitalícia (RMV) para idosos - número de } \\
\text { benefícios em dezembro }\end{array}$ & IPEA/MDS \\
\hline $\begin{array}{c}\text { Renda Mensal Vitalícia (RMV) para idosos - valor total dos } \\
\text { beneficios em dezembro }\end{array}$ & IPEA/MDS & 2008 \\
\hline Rendimento Mensal Total em julho & $\begin{array}{c}\text { Censo 2010 } \\
\text { (Microdados) }\end{array}$ & 2010 \\
\hline Rendimento em todos os trabalhos & $\begin{array}{c}\text { Censo 2010 } \\
\text { (Microdados) }\end{array}$ & 2010 \\
\hline Em Julho de 2010 qual foi o valor deste rendimento? & $\begin{array}{c}\text { Censo 2010 } \\
\text { (Microdados) }\end{array}$ & 2010 \\
\hline
\end{tabular}

Fonte: Elaboração própria

Visando a análise reducionista dos dados e a eliminação de sobreposições, sem perder a capacidade explicativa das variáveis, foi utilizado o método multivariado da Análise de Componentes Principais (ACP) agrupando-as em três componentes principais. A análise inicial 
embasou em 71 variáreis cobrindo todos os municípios brasileiros. Após a primeira rodada dos dados foram identificadas 68 variáveis correlacionadas com as componentes em um total de 5.620 municípios.

Os dados coletados foram tratados, organizados, e analisados a partir do método Kmeans Cluster, que constrói uma medida de similaridade (agrupamentos homogêneos). A análise de agrupamentos consiste de coleção de diferentes algoritmos que agrupam objetos, e é utilizado quando não há nenhuma hipótese a priori sobre a estrutura ou comportamento dos dados (WANGENHEIM, 2010). Foram feitos 5 clusters identificando o perfil previdenciário dos municípios dependentes. A partir dessa classificação, a análise focou nos municípios identificados como os mais dependentes embasados no rendimento domiciliar obtido por meio do Censo Demográfico (2010).

\section{3- PERFIL SOCIOECONÔMICO E PREVIDENCIÁRIO MUNICIPAL}

Em termos populacionais, os dados do último Censo do IBGE, realizado no ano 2010, revelaram que o Brasil possui 190.755.799 habitantes. Desse total, 124.225.273 se referem aos indivíduos com 15 a 64 anos de idade (65,1\%). O grupo com 60 anos ou mais de idade representa $20.588 .887(10,8 \%)$ dos habitantes.

De acordo com o Estatuto, vigente desde janeiro de 2004, houve a redução da idade mínima para acesso ao benefício assistencial de 67 para 65 anos. A cobertura previdenciária, tanto dos trabalhadores economicamente ativos quanto dos idosos inativos, é de fundamental importância para garantir proteção aos trabalhadores e seus dependentes. Com base em um estudo lançado em 2012 do Ministério da Previdência Social, apoiado nos dados de 2011 da Pesquisa Nacional por Amostra de Domicílios (Pnad), a população ocupada (POC) - pessoas com idade entre 16 e 59 anos - compreendia 85,55 milhões de habitantes sendo 60,47 milhões cobertos pelo sistema previdenciário (70,7\%). Em comparação com 2009 tanto a POC quanto a população protegida aumentaram, indicando um aquecimento no mercado formal de trabalho brasileiro. Os que não estão protegidos se configuram por não contribuírem para a Previdência Social, não recebem benefícios previdenciários e não se enquadram na categoria de segurados especiais. Estes somam 25,08 milhões de brasileiros - 29,3\% da POC (Pnad, 2011). Cabe ressalva que existem ainda 910.000 pessoas que não contribuíram para a previdência, mas que recebem algum tipo de auxílio. 
A aplicação do método k-means cluster pelo programa SPSS permitiu a identificação de cinco grupos de municípios com perfil previdenciário diferenciado, a seguir caracterizados.

O cluster 1, abrange 2.257 municípios e 20.374 .303 habitantes, entre 15 e 64 anos (dados de 2010) e uma população idosa de 2.364 .334 (acima de 65 anos). A maior parte dos seus municípios concentra-se nas regiões norte e nordeste. Desse total 12,6\% (284) estão no Estado da Bahia e 9,4\% (213) em Minas Gerais. Em 2010 foram emitidos4 R $\$ 4.278 .800,00$ de benefícios pela Previdência para esses municípios - umaA aplicação do método k-means cluster pelo programa SPSS permitiu a identificação de cinco grupos de municípios com perfil previdenciário diferenciado, a seguir caracterizados.

O cluster 1, abrange 2.257 municípios e 20.374 .303 habitantes, entre 15 e 64 anos (dados de 2010) e uma população idosa de 2.364 .334 (acima de 65 anos). A maior parte dos seus municípios concentra-se nas regiões norte e nordeste. Desse total 12,6\% (284) estão no Estado da Bahia e 9,4\% (213) em Minas Gerais. Em 2010 foram emitidos ${ }^{4} \mathrm{R} \$ 4.278 .800,00 \mathrm{de}$ benefícios pela Previdência para esses municípios - umamédia de quase $\mathrm{R} \$ 3.000,00$ por município - totalizando $\mathrm{R} \$ 26.150 .148 .671,00$ e uma arrecadação ${ }^{5}$ de $\mathrm{R} \$ 3.595 .994 .302,00$. Dessa forma, pode-se constatar que o Cluster 1 caracteriza os municípios com alta dependência de transferência pública previdenciária.

O cluster 2 engloba 8 capitais, a saber: Brasília, Salvador, Maceió, Manaus, Goiânia, São Luís, Belém e Teresina. Caracterizam-se por cidades com população acima de 800mil habitantes, com graus de urbanização acima de $94 \%$, todas com população feminina superior à masculina e população majoritária entre 15 a 64 anos quando se analisa por faixa etária, conforme a Tabela 2. Para essas capitais, 1.352 .794 beneficiários são atendidos pela Previdência arrecadando em torno de $\mathrm{R} \$ 20.169 .331 .865,00$ (em valores correntes). Sendo R \$65.502.973,70 em BPC para os deficientes e R $\$ 72.702 .531,5$ para os idosos (referenciado ano de 2010).

\footnotetext{
${ }^{4} \mathrm{O}$ Valor dos benefícios emitidos corresponde ao valor líquido (diferença entre valor bruto e descontos) dos créditos emitidos pelo Instituto Nacional de Previdência Social - INSS para pagamento de benefícios do Regime Geral de Previdência Social, Encargos Previdenciários daUnião e Amparos Assistenciais, classificados de acordo com o município do órgão pagador e clientela (DATAPREV, 2013).

${ }^{5}$ Valor arrecadado considera os recolhimentos provenientes de todas as receitas incluídas nas Guias da Previdência Social - GPS, de janeiro a dezembro de cada ano. Abrangem receitas de contribuições sociais - empresas, entidades equiparadas e contribuintes em geral, débitos e parcelamentos (administrativo e judicial), patrimoniais, devolução de benefícios, reclamatória trabalhista e outros (DATAPREV, 2013).
} 
Tabela 2: População por faixa etária do cluster 2 - 2010

\begin{tabular}{|c|c|c|c|c|c|c|c|}
\hline Município & $\begin{array}{c}\text { População de 0 } \\
\text { a 14 anos }\end{array}$ & \% & $\begin{array}{c}\text { População de 15 } \\
\text { a 64 anos }\end{array}$ & $\%$ & $\begin{array}{c}\text { População de 65 } \\
\text { anos ou mais }\end{array}$ & Total \\
\hline Maceió & 233.452 & 25 & 648.367 & 70 & 50.928 & 5 & 932.747 \\
\hline Manaus & 508.141 & 28 & 1.224 .101 & 68 & 69.772 & 4 & 1.802 .014 \\
\hline Salvador & 553.305 & 21 & 1.957 .137 & 73 & 165.214 & 6 & 2.675 .656 \\
\hline Brasília & 608.349 & 24 & 1.833 .683 & 71 & 128.128 & 5 & 2.570 .160 \\
\hline Goiânia & 270.906 & 21 & 949.607 & 73 & 81.487 & 6 & 1.302 .000 \\
\hline São Luís & 240.378 & 24 & 721.293 & 71 & 53.166 & 5 & 1.014 .837 \\
\hline Belém & 324.934 & 23 & 981.435 & 70 & 87.030 & 6 & 1.393 .399 \\
\hline Teresina & 190.487 & 23 & 576.802 & 71 & 46.942 & 6 & 814.231 \\
\hline
\end{tabular}

O cluster 3 se refere apenas ao município de São Paulo, que possui uma população de 11.253.503, sendo 8,3\% acima de 65 anos. Possui o maior PIB do Brasil R $\$ 188.006 .857,00$ seguido do Rio de Janeiro 84.867.058,40 (valores correntes de 2010). Em 2010 arrecadou R\$ 51.460.936.802,00 da previdência. Em relação ao número de BPC emitidos até dezembro de 2010, do total de 163.730 (deficientes e idosos), 65,0\% foram destinados aos idosos do município, somando um valor de $\mathrm{R} \$ 53.854 .848,50$. Este cluster não caracteriza dependência de transferência de recurso da Previdência Social.

O cluster 4, abrange 2.621 municípios, nas regiões sul e sudeste, somando 64.333 .533 habitantes com quase 8\% de população idosa. No ano de 2010 foram beneficiados 472.066 idosos com a BPC, que garante à eles carentes uma renda mensal, de um salário mínimo, para sua sobrevivência.

E, finalmente, o cluster 5 cobre os 514 municípios restantes, somando 79.015 .576 habitantes, sendo 2.402.412 idosos (3\%). Dos 5.232.647 benefícios emitidos pela Previdência, em 2010, 448.196 foram BPC para idosos e 310.404 para deficientes. Este cluster possui mais municípios na região Centro-Oeste.

Abaixo, a Figura 2 demonstra os clusters especializados a nível municipal. 


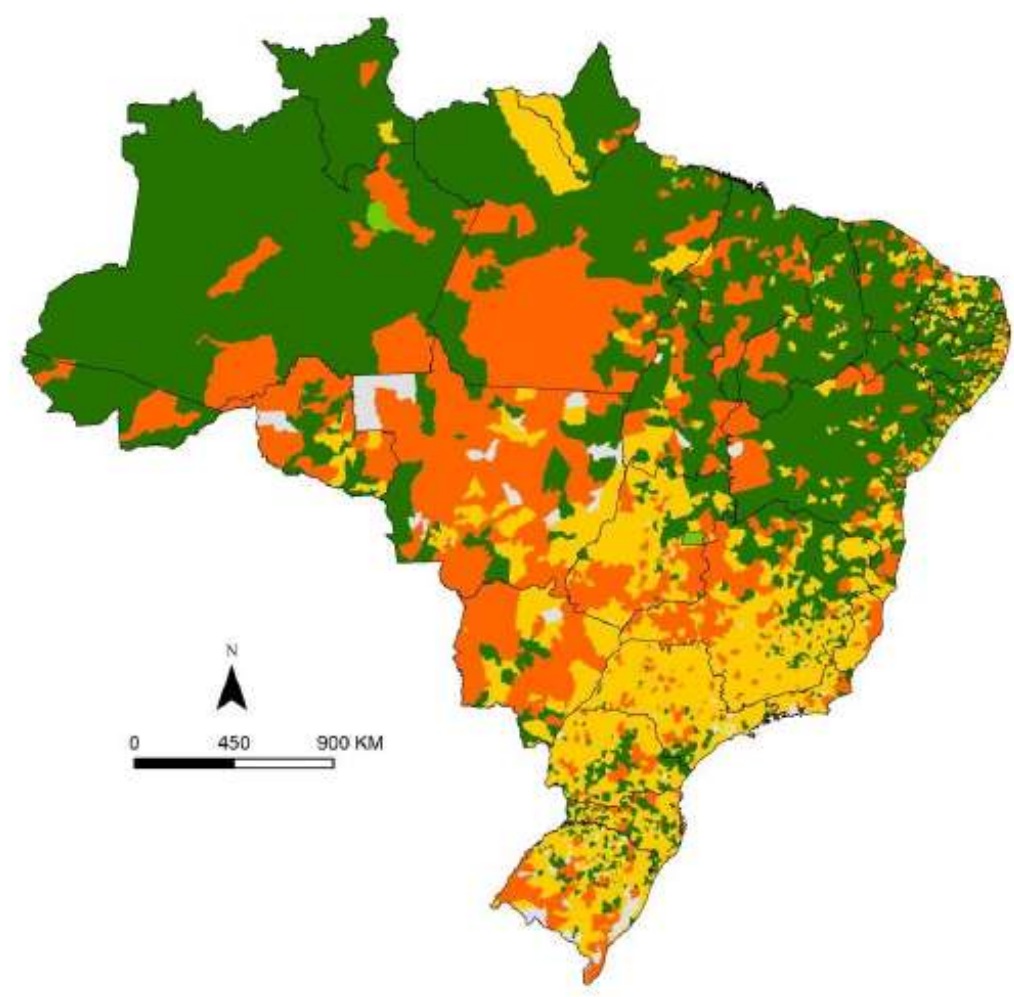

Previdência Pública no Brasil Municipios por Clusters

Figura 2: Distribuição espacial dos municipios brasileiros por cluster. / Elaboração própria.

A Tabela 3 está demonstrando os dados para uma nova abordagem de forma a ter-se outras interpretações mantendo o eixo principal do artigo que é identificar os municípios dependentes das transferências de renda da Previdência Pública no Brasil.Em relação aos dados de beneficiários os clusters 1,4 e 5 possuem maior quantidade de idosos em relação aos deficientes quando se trata de BPC. Para os dados do Censo Demográfico de 2010 em relação ao rendimento mensal, feita por domicílios, gerou-se uma espécie de indicador que retrata a massa salarial, ou seja, o poder de compra dos habitantes (consumo x produção). Esse indicador surgiu da razão entre a soma dos rendimentos advindos de outras fontes ${ }^{6}$, como da Previdência Social e do rendimento mensal habitual do trabalho principal da semana de referência (julho de 2010). Assim, ao operacionalizar este conceito, o indicador ressaltou o cluster 1 que obteve uma dependência de 35,2\% desses rendimentos advindos de outras fontes.

\footnotetext{
${ }^{6}$ Esse rendimento é o somatório de aposentadoria e pensão de instituto de previdência oficial, Programa Bolsa Família; Programa de Erradicação do Trabalho Infantil (PETI), outros programas sociais e transferências;aposentadoria e pensão da previdência privada; aluguel; juros de caderneta de poupança e de outras aplicações financeiras, etc. (IBGE,2010)
} 
Tabela 3: Dados resumidos por clusters - 2010

\begin{tabular}{|l|c|c|c|c|c|c|c|}
\hline & $\begin{array}{c}\text { Beneficiário } \\
\text { s Totais }\end{array}$ & $\begin{array}{c}\text { BPC } \\
\text { Deficientes }\end{array}$ & BPC Idosos & $\begin{array}{c}\text { Rendimento } \\
\text { Mensal em Julho } \\
\text { 2010 (Total) }\end{array}$ & $\begin{array}{c}\text { Rendimento em } \\
\text { todos os } \\
\text { trabalhos }\end{array}$ & $\begin{array}{c}\text { Qual foi o total } \\
\text { desses rendimentos } \\
\text { em Julho 2010 }\end{array}$ & $\begin{array}{c}\text { Dependên } \\
\text { cia (Massa } \\
\text { Salarial) }\end{array}$ \\
\hline Cluster 1 & 4.278 .800 & 319.162 & 164.875 & 8.811 .184 .252 & 5.710 .784 .654 & 3.100 .399 .605 & 35,2 \\
\hline Cluster 2 & 1.352 .794 & 128.688 & 142.676 & 13.001 .280 .573 & 9.921 .799 .834 & 3.079 .480 .738 & 23,7 \\
\hline Cluster 3 & 1.736 .830 & 58.061 & 105.669 & 15.888 .752 .585 & 11.983 .128 .591 & 3.905 .623 .994 & 24,6 \\
\hline Cluster 4 & 11.173 .428 & 554.418 & 472.066 & 47.826 .349 .836 & 35.667 .607 .304 & 12.158 .742 .518 & 25,4 \\
\hline Cluster 5 & 5.232 .647 & 493.344 & 448.196 & 25.823 .052 .334 & 20.130 .527 .724 & 5.692 .524 .612 & 22,0 \\
\hline
\end{tabular}

Para compreender melhor essa dependência, fez-se uma nova abordagem dos dados para descobrir quais municípios de fato dependem das transferências, ou seja, possuem pouca capacidade econômica produtiva. Essa dependência foi aqui entendida, no primeiro momento, como aqueles municípios que obtiveram o índice acima de 35,0\%. No segundo momento, a análise é voltada para a redução desses municípios que registraram o valor acima de 50,0\%.

$\mathrm{Na}$ análise dos municípios que apresentaram valores acima de 35,0\% somaram-se 1.889 sendo 70,2\% (1.327) na região Nordeste, 18,2\% (343) na Sudeste, 7,3\% (137) na Sul, 2,4\% (45) na Norte e 2,0\% (37) no Centro- Oeste (Figura 3).

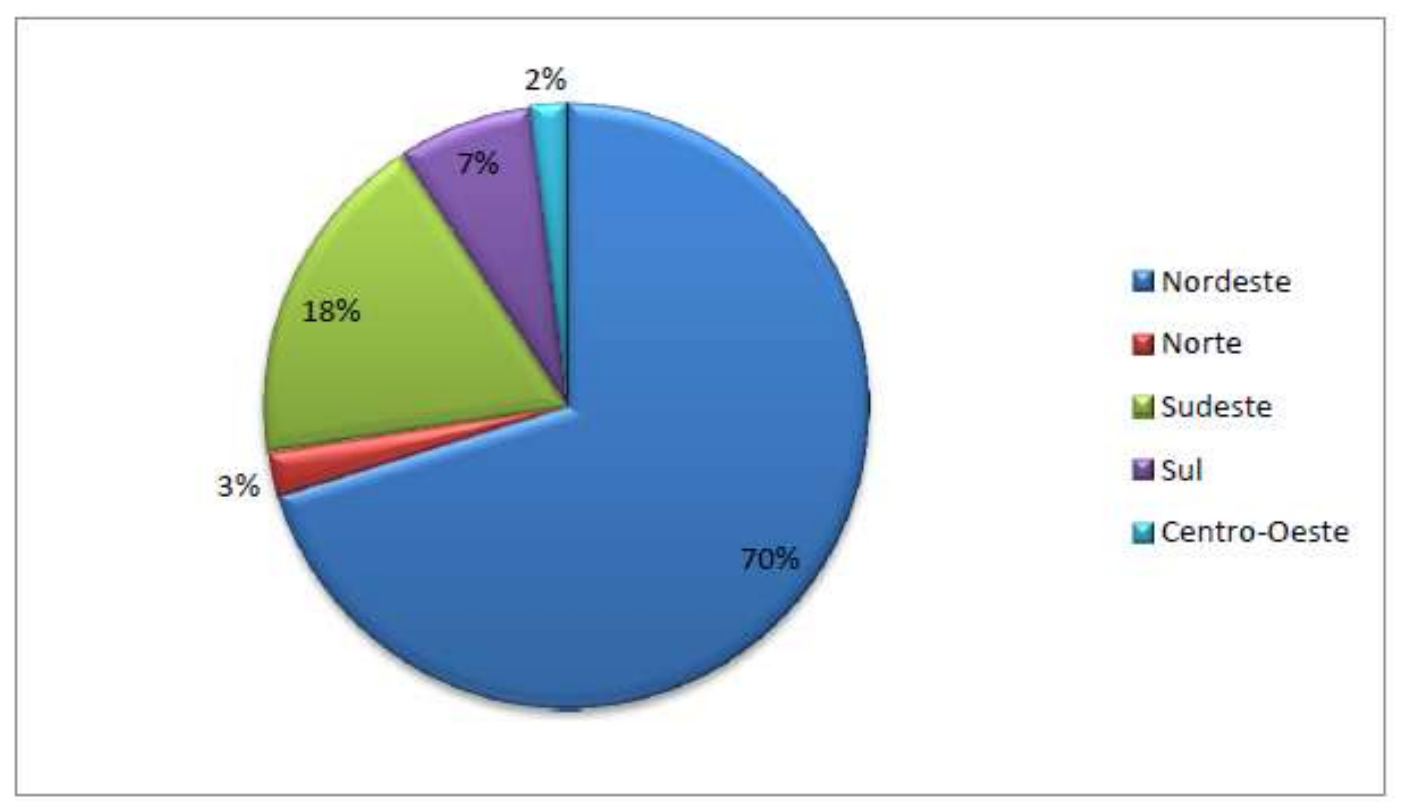

Figura 3: Porcentagem dos municípios dependentes em relação à região - acima de $35,0 \%$ / Elaboração própria.

A espacialização dos municípios com valores do indicador acima de 35,0\% se assemelham à do cluster 1, analisado anteriormente (Figura 4). 


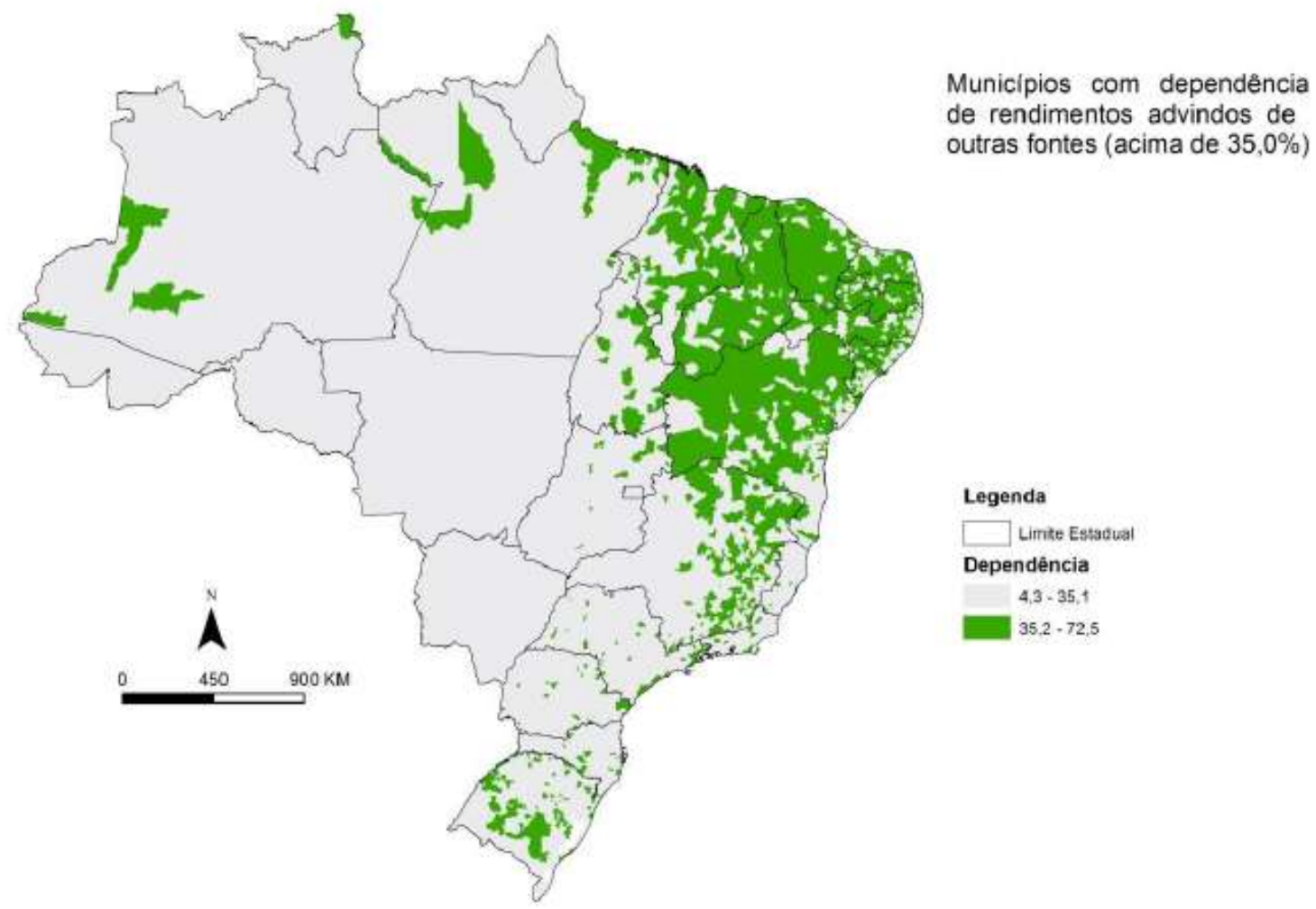

Figura 4: Distribuição espacial dos municípios dependentes de outras fontes de renda - acima de 35,0\% / Elaboração própria.

No segundo momento, fazendo a análise dos dados para aqueles municípios que registraram o indicador acime de 50,0\%, tem-se a redução dos municípios classificados anteriormente pelos clusters como dependentes a partir das variáveis iniciais e vê-se claramente que se concentram na região nordeste do país (Figura 5). 


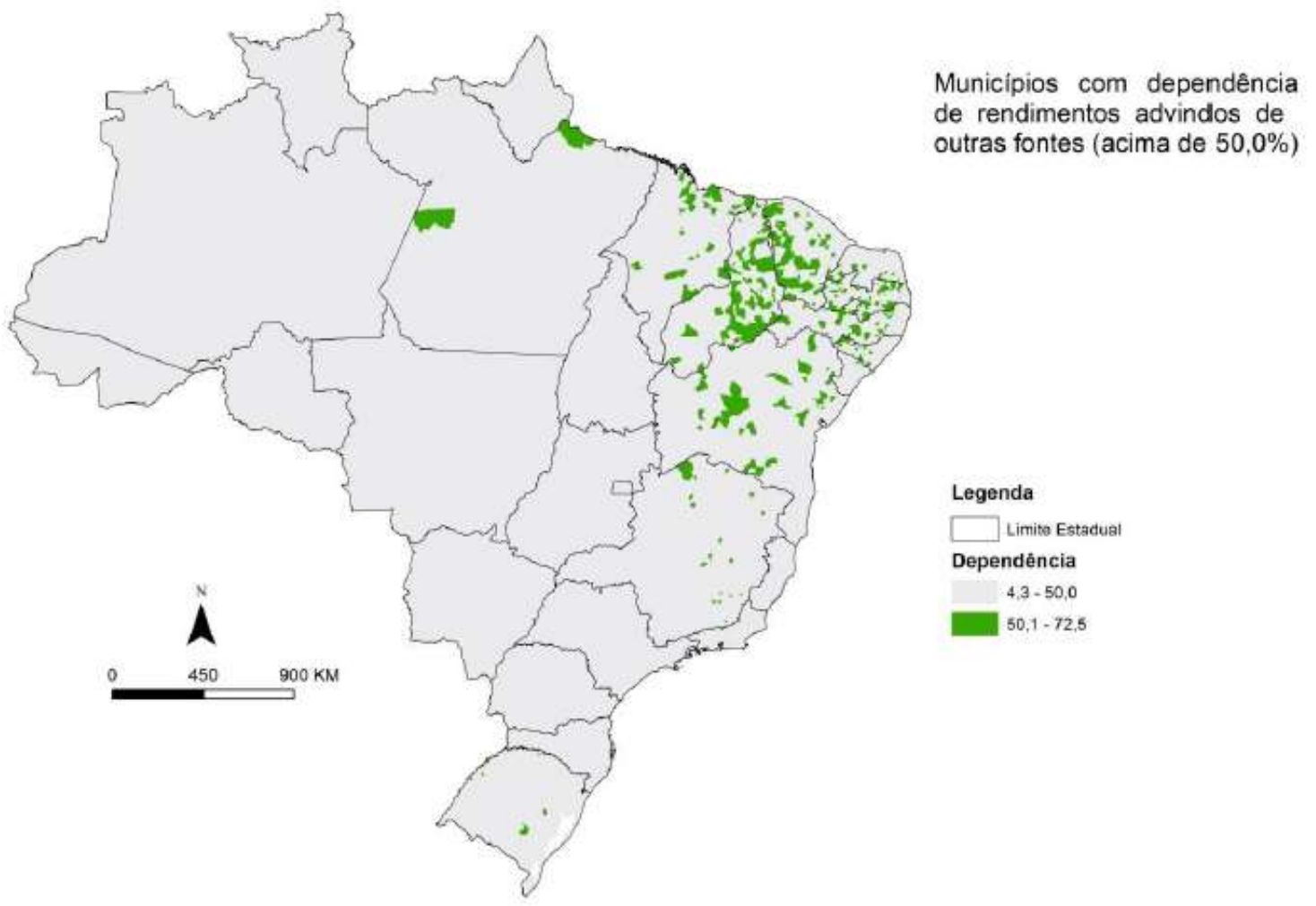

Figura 5: Distribuição espacial dos municípios dependentes de outras fontes de renda - acima de 50,0\% / Elaboração própria.

A Figura 6 apresenta a distribuição em porcentagem das regiões em relação ao peso dos municípios dependentes. A região Nordeste possui 319 municípios dos 345 mapeados como dependentes, seguido pela Sudeste (18), Sul (6) e Norte (2). 


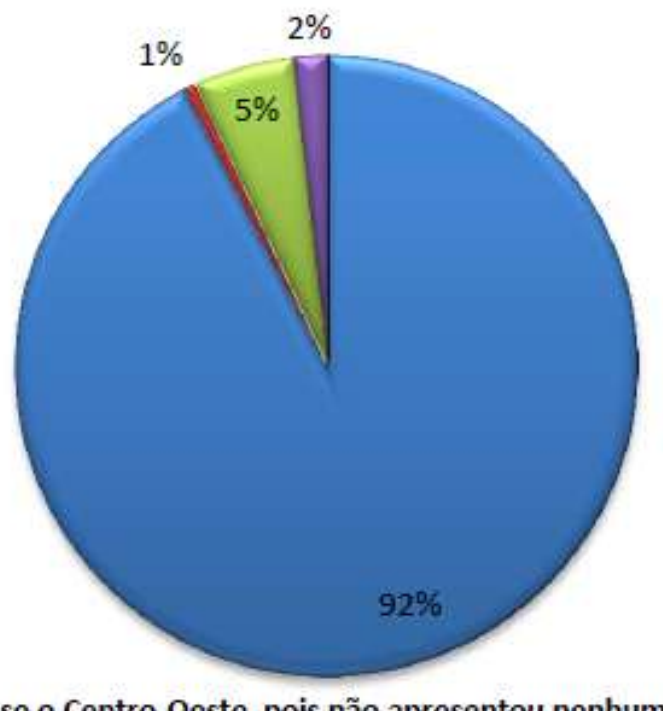

Nordeste

Norte

MSudeste

asul

* Retirou-se o Centro-Oeste, pois não apresentou nenhum municipio.

Figura 6: Porcentagem dos municípios dependentes em relação à região - acima de 50,0\% / Elaboração própria.

\section{5- CONSIDERAÇÕES FINAIS}

Como foi visto é fato que os dados em relação à população economicamente ativa e aos idosos estão aumentando a cada ano, no mesmo ritmo que a formalidade do trabalho, o que possibilita o aumento gradativo de contribuição mensal à Previdência. Outro fator que contribui para esse crescimento são as políticas relacionadas à inclusão previdenciária (Empreendedor Individual e Programa Donas de Casa de Baixa Renda). Só que ao analisarmos esses dados a nível municipal, deve-se atentar pelo fato da grande massa salarial do município ser resultante dessas transferências, indicando um município sem economia forte, dinâmica e independente suficiente para gerar renda interna. Viu-se que 34,0\% dos municípios brasileiros possuem dependência de transferência quando analisamos àqueles com valores acima de 35,0\%. É uma quantidade considerável quando pensamos na quantidade de indivíduos dependentes dessa renda, ou seja, do Estado.

A partir dos dados trabalhados pode-se ter mais clareza de onde estão distribuídos os municípios com economia formada por essas características, em especial, a da aposentadoria emitida pela Previdência Social (e INSS). Como já levantado por Gomes (1997) e recente por Gustavo Maia Gomes (2001) em um dos capítulos do seu livro Velhas secas em novos sertões, a região Nordeste, principalmente o semi-árido pode sim, ser definida como economia sem 
produção uma vez que depende e muito da transferência de renda do Bolsa Família, dos salários dos aposentados e funcionários públicos.

\section{6- REFERÊNCIAS BIBLIOGRÁFICAS}

ABRAMOVAY, R. Limites da “economia sem produção”. Gazeta Mercantil, São Paulo: 24 de janeiro de 2002.

BERTUSSI, Luís Antônio Sleimann; TEJADA, César A. O.. Teoria e Evidência Econômica: conceito, estrutura e evolução da Previdência Social no Brasil. Passo Fundo, RS, 2003.

GOMES, G. M. Velhas secas em novos sertões: continuidade e mudanças na economia dosemi-árido e dos cerrados nordestinos. Brasília: Ipea, 2001.

IPEA,2013.Programa Bolsa Família : uma década de inclusão e cidadania/organizadores: Tereza Campello, Marcelo Côrtes Neri. Brasília : Ipea, 2013.

MIRANDA, ANDREY L. F. o déficit da previdência social: análise comparativa entre as duas linhas metodológicas divergentes. Monografia submetida ao curso de Ciências Econômicas da Universidade Federal de Santa Catarina, como requisito obrigatório para a obtenção do grau de Bacharel em Ciências Econômicas Florianópolis, 2010. Disponível em: http://tcc.bu.ufsc.br/Economia292766

RUPRECHT, Alfredo J. Direito da Seguridade Social. São Paulo: ed. Ltr, 1996.

TONATTO, Neivaldo. Previdência Privada: planos individuais de complementação de renda na aposentadoria comparados a outras formas de investimentos. Novo Hamburgo, 2003, 118 p. Trabalho de Conclusão (Bacharelado de Ciências Contábeis) Instituto de Ciências Sociais Aplicadas, FEEVALE, 2003.

WANGENHEIM , Aldo von. Reconhecimento de Padrões, Métodos, Técnicas e Ferramentas para Aprendizado e Classificação. Disponível em: www.inf.ufsc.br/ patrec/agrupamentos.html 